\title{
Chemical Composition and Antimicrobial Activity of the Essential Oil of Tanacetum persicum
}

\author{
Forough Mahdian, ${ }^{1}$ Mohaddese Mahboubi, ${ }^{2,}{ }^{*}$ Ebrahim Rahimi, ${ }^{3}$ and Maryam Moslehi Shad ${ }^{4}$ \\ ${ }^{1}$ Department of Food Science and Technology, Faculty of Advanced Sciences \& Technology, Pharmaceutical Sciences Branch, Islamic Azad University, Tehran, IR Iran \\ ${ }^{2}$ Department of Microbiology, Medicinal Plant, Research Center of Barij, Kashan, IR Iran \\ ${ }^{3}$ Department of Food Hygiene and Public Health, Faculty of Veterinary Medicine, Shahrekord Branch, Islamic Azad University, Shahrekord, IR Iran \\ ${ }^{4}$ Department of Food Science and Technology, Safadasht Branch, Islamic Azad university, Tehran, Iran \\ "Corresponding author: Mohaddese Mahboubi, Department of Microbiology, Medicinal Plant, Research Center of Barij, Kashan, IR Iran. Tel: +98-8644465112, Fax: \\ +98-8644465112, E-mail: mahboubi@barijessence.com, mahboubi1357@yahoo.com
}

Received 2015 December 27; Revised 2016 March 16; Accepted 2016 April 24.

\begin{abstract}
Background: Tanacetum persicum (Boiss.) Mozaff is a plant with a long history in Iranian traditional medicine as an antiseptic medicinal plant. Objectives: This study aimed to evaluate the antimicrobial and antioxidant activities of T. persicum essential oil and analyze its chemical composition.

Methods: In this study, the chemical composition of the aerial part essential oil of T. persicum was analyzed by gas chromatography and gas chromatography-mass spectroscopy apparatuses. Antimicrobial activity was evaluated against Helicobacter pylori, Staphylococcus aureus, and Salmonella enterica by disc diffusion and micro-broth dilution assays.

Results: The antioxidant activity of the essential oil was compared with ascorbic acid against ABTS free radicals. Borneol (33.5\%), bornyl acetate (12.8\%), and linalool (9.1\%) were the main components of the essential oil of T. persicum. S. aureus, which has a high inhibition zone diameter (mm) and low minimal inhibitory concentration and minimal bactericidal concentration values, showed the most sensitivity to essential oil, followed by S. enterica and H. pylori. The antioxidant activity of the essential oil was the same as that of ascorbic acid $\left(\mathrm{IC}_{50}=20 \mathrm{ppm}\right)$.

Conclusions: The essential oil of T. persicum is a good source of borneol and a valuable antioxidant and antimicrobial agent.

Keywords: Tanacetum persicum, Essential Oil, Antioxidant, Antimicrobial, Borneol, Linalool
\end{abstract}

\section{Background}

The genus Tanacetum L. (Asteraceae family) has 26 annual herbaceous plants in Iran (1). The Tanacetum species is a group of plants with a long tradition of being used as preservatives and herbal drugs (2). In traditional medicine, these plants are used for the treatment of fever, inflammation, women's conditions such as dysmenorrhea and facilitating delivery, psoriasis, toothache, and stomachache (3). Tanacetum persicum (Boiss.) Mozaff., which is endemic to Iran, has not been studied well thus far.

Different research resources showed that only one study has identified the chemical composition of the aerial part essential oil of T. persicum (Dehdez, Province of Khuzestan, Iran) (4). Borneol (24.3\%), menthyl acetate (17.3\%), isobornyl 2-methyl butyrate (16\%), and artedouglasia oxide $\mathrm{D}(14.3 \%)$ were the main components of the essential oil of T. persicum.

\section{Objectives}

In this study, we evaluated the antibacterial property of the essential oil of T. persicum (Boiss.) Mozaff. against three important pathogenic bacteria, namely, Staphylococcus aureus, Salmonella enterica, and Helicobacter pylori. The antiox- idant activity of the essential oil of T. persicum was screened against ABTS free radicals.

\section{Methods}

\subsection{Plant Material}

The aerial parts of $T$. persicum were collected from Chahar-Va-Mahal Bakhtiari Province, Iran, in June 2015. Voucher specimens were deposited at the herbarium center of Islamic Azad University, Tehran, Iran.

3.2. Essential Oil Extraction and Chemical Composition Determination by Gas Chromatography (GC) and Gas Chromatography-Mass Spectroscopy (GC-MS) Analysis

The essential oil from air-dried aerial parts of $T$. persicum was obtained by hydro distillation using a Clevengertype apparatus for 3 hours. The essential oil was dried over anhydrous sodium sulfate.

The essential oil underwent GC analysis using Agilent 5975 C technology (HP-5 MS) with a capillary column of HP1MS (30 m $\times 0.25 \mathrm{~mm}$, film thickness $0.25 \mu \mathrm{m}$ ) and GCMS analysis using Agilent technology (HP) 6890 coupled with a 5975 network mass selective detector system. The oven temperature program was initiated at $60^{\circ} \mathrm{C}$, held for 
1 minute and increased to $280^{\circ} \mathrm{C}$ at a rate of $3^{\circ} \mathrm{C} / \mathrm{min}$, and then held for 10 minutes. Helium was used as the carrier gas at a flow rate of $1.0 \mathrm{ml} / \mathrm{min}$ with a split ratio equal to 1/50 injector. The detector and injector temperatures were $250^{\circ} \mathrm{C}$ and $230^{\circ} \mathrm{C}$, respectively. Components of the essential oil were identified by comparison with Retention Indices (RI) relative to the homologous series of n-alkanes, and the results were determined using the libraries of Wiley 275.L and Wiley $7 n .1(5)$.

\subsection{Microbial Strains and Antimicrobial Activity Evaluation}

S. enterica BAA-708, H. pylori ATCC 26695, and S. aureus ATCC 25923 were used in this study. The bacteria were cultured on suitable agar mediums and incubated at $30^{\circ} \mathrm{C}$ - $35^{\circ} \mathrm{C}$ in suitable conditions separately. The turbidity of each bacterium was adjusted to 0.5 McFarland by Spectrophotometer instruments $\left(1 \times 10^{8} \mathrm{CFU} / \mathrm{ml}\right)$ by inoculating one or two colonies of each strain into normal saline solution.

The antibacterial activity of the essential oil was evaluated by two different methods, namely, disc diffusion and micro-broth dilution assays.

In the disc diffusion method, the inhibition zone diameters ( $\mathrm{mm}$ ) of the essential oil against bacteria were determined by inoculating the above microbial strains $(1 \times$ $10^{8} \mathrm{CFU} / \mathrm{ml}$ ) into the agar media culture by sterile cotton swabs. Sterile disks containing $5 \mu$ l of essential oil were placed on these inoculated plates and then incubated. The inhibition zone diameters were measured and reported as means \pm standard deviation (6).

The minimal inhibitory concentration (MIC) and minimal bactericidal concentration (MBC) values of the essential oil in the micro-broth dilution assay were determined by dissolving the essential oil in DMSO (stock solution) and then serially diluting it in distilled water (6-0.094 $\mu \mathrm{l} / \mathrm{ml})$. A total of $100 \mu \mathrm{l}$ of each dilution was added into the wells of 96-microtiter plates. Then, $100 \mu \mathrm{l}$ of diluted microbial suspensions $\left(10^{6} \mathrm{CFU} / \mathrm{ml}\right)$ were added to each well and incubated at $37^{\circ} \mathrm{C}$ for 24 hours. The first wells with no turbidity and the first well without any growth on the solid media were determined as the MIC and MBC values, respectively (7).

\subsection{Antioxidant Evaluation of the Essential Oil by ABTS Radicals}

The antioxidant activity of the essential oil against ABTS free radicals was determined by preparing a solution containing $7 \mathrm{mM}$ ABTS in $2.45 \mathrm{mM}$ persulfate (1:1). This solution was kept in a dark place (12 - 16 hours) and then diluted to 1:25. Different concentrations of essential oil were prepared. About $3 \mathrm{ml}$ of ABTS solution was added to $40 \mu \mathrm{l}$ of different concentrations of essential oil. After $15 \mathrm{~min}$, the absorbance of each concentration was read at $734 \mathrm{~nm}$, and the inhibition percent of the essential oil were estimated as follows:

$I \%=\left[\frac{A_{\text {blank }}-A_{\text {sample }}}{A_{\text {blank }}}\right] \times 100$

Where $A_{\text {blank }}$ is the absorbance of the control and $\mathrm{A}_{\text {sample }}$ is the absorbance of the different concentrations of essential oil. Ascorbic acid was used as the control (8).

\section{Results and Discussion}

Forty components were identified in the essential oil of T. persicum, and they represented $82.5 \%$ of the total essential oil composition. Borneol (33.5\%), bornyl acetate (12.8\%), linalool (9.1\%), 1- hexane 3-en-2,5,5, and trimethyl (6.8\%) were the main components of the essential oil of $T$. persicum (Table 1 ).

The first main component of the essential oil of T. persicum in this study was consistent with the first major component found by Habibi et al. (4), who reported borneol (24.3\%) as the main component of the essential oil of T. persicum. The other main components were different from those in the other study. The second main component of T. persicum essential oil from Shahr-E-Kord was bornyl acetate, and that from Khuzistan Province was menthyl acetate (4).

Generally regarded safe by the food and drug administration, borneol $(\mathrm{C} 10 \mathrm{H} 18 \mathrm{O})$ is used as an important ingredient in food and medicine and as food flavoring (9). Some biological activities of borneol, such as central and peripheral antinociceptive effects (10), vaso-relaxant effect on rat thoracic aorta (11), and neuroprotective activity (12), have been confirmed. Therefore, because of the high amount of borneol in the essential oil of T. persicum, this essential oil can be used for different purposes in the food and pharmaceutical industries.

The antibacterial activity evaluation of the essential oil of $T$. persicum against three different pathogenic bacteria was evaluated. In the disc diffusion assay, S. aureus had the highest inhibition zone diameter $(23 \mathrm{~mm})$, followed by $S$. enterica $(20 \mathrm{~mm})$ and $H$. pylori $(17 \mathrm{~mm})$. In the micro broth dilution assay, S. aureus had MIC and MBC values of 0.325 and $0.75 \mu \mathrm{l} / \mathrm{ml}$, and it showed the highest sensitivity to the essential oil of T. persicum, followed by S. enterica (MIC and MBC values of 0.75 and $1.5 \mu \mathrm{l} / \mathrm{ml}$ ) and H.pylori (MIC and MBC values of 0.75 and $3 \mu \mathrm{l} / \mathrm{ml}$ ), respectively. Although the MIC values of the essential oil of T. persicum for S. enterica and $H$. pylori were the same, the effects of this essential oil on $H$. pylori was inhibitory, and higher doses of the essential oil was required to kill this bacterium (Table 2). 


\begin{tabular}{|c|c|c|c|c|}
\hline & \multicolumn{2}{|c|}{ Disc Diffusion, mm } & \multicolumn{2}{|c|}{ Micro-broth Dilution Assay, $\mu \mathrm{l} / \mathrm{ml}$} \\
\hline & E.platyloba & Tetracycline & MIC & MBC \\
\hline Salmonella enterica & 20 & 20.8 & $0.75 \pm 0.03$ & $1.5 \pm 0.05$ \\
\hline Helicobacter pylori & 17 & 21 & $0.75 \pm 0.02$ & $3.0 \pm 0.03$ \\
\hline
\end{tabular}

Abbreviations: MBC, Minimal Bactericidal Concentration; MIC, Minimal Inhibitory Concentration.

The antimicrobial activity of borneol was confirmed against Candida albicans, S. aureus, and Escherichia coli (13). Furthermore, the antibacterial activities of some oxygenated monoterpenes, such as borneol, borneol acetate, camphor, 1,8-cineol, linalool, terpinen-4-ol, and $\alpha$ terpineol, were evaluated against 63 bacteria strains, and these compounds were confirmed to have different degrees of antibacterial activities against different bacteria. However, some compounds such as linalool, $\alpha$-terpineol, and terpinen-4-ol, have extended limited antibacterial effects, and compounds such as camphor and 1,8-cineol showed no antibacterial activity (14). Therefore, the considerable antibacterial activity of the essential oil of T. persicum is related to the major or minor components present in this essential oil.

The antioxidant evaluation of the essential oil of T. persicum showed that $\mathrm{IC}_{50}$ was equal to $20 \mathrm{ppm}$ and that this essential oil was the same as ascorbic acid in being a synthetic antioxidant. At a high concentration of the essential oil of $T$. persicum, the antioxidant activity of this essential oil was higher than that of ascorbic acid (Figure 1).

The antioxidant activity of thymol and carvacrol was reported previously (15). Borneol was confirmed to have no antioxidant activity in the antioxidant system, but it could protect cell DNA against $\mathrm{Fe}^{2+}$-induced damage (15). Therefore, the other components of the essential oil or the syner-

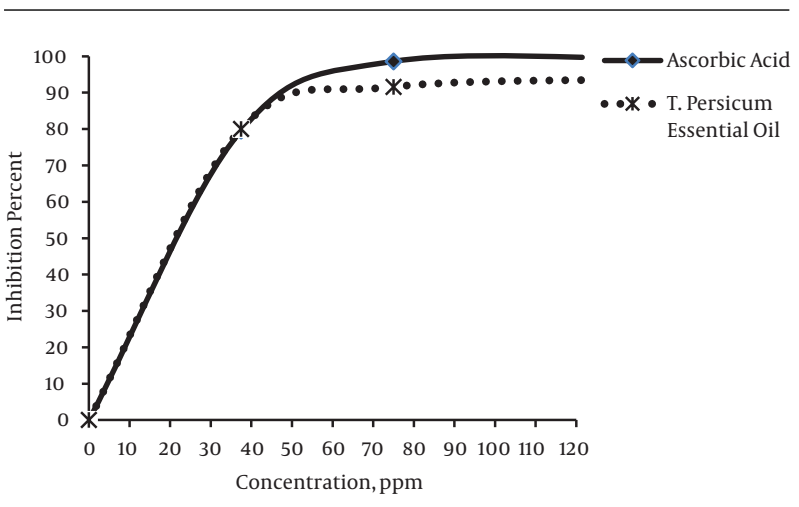

Figure 1. Antioxidant Activity of the Essential Oil of T. persicum gistic effect among compounds plays an important role in the antioxidant potency of the essential oil. Linalool, the other main component of the essential oil, is a lead compound in the synthesis of vitamins A and E. Linalool-rich essential oils were confirmed to express a high antioxidant activity (16).

Therefore, the antioxidant activity of the essential oil of T.persicum is related to linalool or its other components. This essential oil can be a suitable antioxidant agent for human consumption and a preservative in food or drugs instead of chemical ones.

\section{Conclusion}

For the first time, the essential oil of T. persicum was shown to have desirable antioxidant and antimicrobial activities in vitro because of its main components, namely, borneol, bornyl acetate, and linalool. As the other pharmacological activities (i.e., anti-inflammatory, antinociceptive, and analgesic) of borneol and linalool have already been confirmed, the other pharmacological activities of this valuable plant aside from its antioxidant and antimicrobial effects can be investigated to introduce the essential oil of T. persicum as a new treatment for other ailments.

\section{Footnotes}

Authors' Contribution: Forough Mahdian performed the experiment; Mohaddese Mahboubi prepared the draft of the manuscript, gathered data, and interpreted the findings; and Ebrahim Rahimi and Maryam Moslehi Shada designed and supervised the project.

Funding/Support: This study was supported by the Pharmaceutical Sciences Branch, Islamic Azad University, Tehran, Iran.

\section{References}

1. Mozaffarian V. A dictionary of Iranian Plant Names. Tehran: Farhang Moaser; 1996.

2. Hussey J. Some useful plants of early new England. Econ Bot. 1974;28(3):311-37. 
3. Kumar V, Tyagi D. Chemical composition and biological activities of essential oils of genus tanacetum-a review. J Pharmacog Phytochem. 2013;2(3):155-9.

4. Habibi Z, Hejazi Y, Alipour S, Masoudi S, Rustaiyan A. Essential oils of tanacetum elburensis mozaff. And tanacetum persicum (boiss.) mozaff. From Iran. J Essential Oil Res. 2007;19(4):310-2.

5. Adams RP. Identification of essential oil components by gas chromatography/mass spectroscopy. J Am Soc Mass Spectrom. 1997;6(8):671-2.

6. CLSI . Performance standards for antimicrobial disc susceptibility test. Tentative standard, M02-A12.12 ed.32. Wayne, Pennsylvania: CLSI; 2015.

7. CLSI . Methods for dilution antimicrobial susceptibility tests for bacteria that grow aerobically; approved standard-M07A102015. Wayne, Pennsylvania: CLSI; 2015.

8. Miliauskas G, Venskutonis PR, Van Beek TA. Screening of radical scavenging activity of some medicinal and aromatic plant extracts. Food Chemistry. 2004;85(2):231-7.

9. Shen Q, Li X, Li W, Zhao X. Enhanced intestinal absorption of daidzein by borneol/menthol eutectic mixture and microemulsion. AAPS PharmSciTech. 2011;12(4):1044-9. doi: 10.1208/s12249-011-9672-4. [PubMed: 21842308].

10. Almeida JR, Souza GR, Silva JC, Saraiva SR, Junior RG, Quintans Jde S, et al. Borneol, a bicyclic monoterpene alcohol, reduces nociceptive behavior and inflammatory response in mice. ScientificWorldJournal. 2013;2013:808460. doi: 10.1155/2013/808460. [PubMed: 23710149].
11. Silva-Filho JC, Oliveira NN, Arcanjo DD, Quintans-Junior LJ, Cavalcanti SC, Santos MR, et al. Investigation of mechanisms involved in (-)-borneol-induced vasorelaxant response on rat thoracic aorta. Basic Clin Pharmacol Toxicol. 2012;110(2):171-7. doi: 10.1111/j.17427843.2011.00784.x. [PubMed: 21883938].

12. Liu R, Zhang L, Lan X, Li L, Zhang TT, Sun JH, et al. Protection by borneol on cortical neurons against oxygen-glucose deprivation/reperfusion: involvement of anti-oxidation and anti-inflammation through nuclear transcription factor kappaappaB signaling pathway. Neuroscience. 2011;176:408-19. doi: 10.1016/j.neuroscience.2010.11.029. [PubMed: 21168474].

13. Al-Farhan KA, Warad I, Al-Resayes SI, Fouda MM, Ghazzali M. Synthesis, structural chemistry and antimicrobial activity of (-) borneol derivative. Cent Eur J Chem. 2010;8(5):1127-33.

14. Kotan R, Kordali S, Cakir A. Screening of antibacterial activities of twenty-one oxygenated monoterpenes. Z Naturforsch C. 2007;62(78):507-13. [PubMed:17913064].

15. Horvathova E, Navarova J, Galova E, Sevcovicova A, Chodakova L, Snahnicanova Z, et al. Assessment of antioxidative, chelating, and DNA-protective effects of selected essential oil components (eugenol, carvacrol, thymol, borneol, eucalyptol) of plants and intact Rosmarinus officinalis oil. J Agric Food Chem. 2014;62(28):6632-9. doi: 10.1021/jf501006y. [PubMed: 24955655].

16. Aprotosoaie AC, Hancianu M, Costache II, Miron A. Linalool: a review on a key odorant molecule with valuable biological properties. Flavour Frag J. 2014;29(4):193-219. 
Table 1. Chemical Composition of the Essential Oil of T. persicum by GC and GC-MS

\begin{tabular}{|c|c|c|}
\hline Compound & RI & (\%) \\
\hline 1- hexane 3-en-2,5,5, trimethyl & 866 & 6.8 \\
\hline$\alpha$-thujone & 929 & 0.03 \\
\hline$\alpha$-pinene & 936 & 0.5 \\
\hline Camphene & 950 & 2.1 \\
\hline Verbenone & 967 & 0.1 \\
\hline Sabinene & 981 & 0.2 \\
\hline$\beta$-pinene & & 984 \\
\hline 1,5-dimethyl hepta, 1,3,5-trian & 995 & 1.4 \\
\hline$\alpha$-phellandrene & 1006 & 0.3 \\
\hline$\alpha$-terpinene & 1017 & 0.3 \\
\hline p-cymene & 1024 & 0.9 \\
\hline Limonene & 1028 & 0.3 \\
\hline 1,8-cineole & 1030 & 0.7 \\
\hline$\gamma$-terpinene & 1057 & 0.7 \\
\hline Cis-sabinene hydrate trans linalool oxide & 1066 & 0.2 \\
\hline Linalool & 1102 & 9.1 \\
\hline Chrysantenol-trans pinocarveol & 1137 & 0.1 \\
\hline Cis-verbenol & 1139 & 0.2 \\
\hline Camphor & 1145 & 2.1 \\
\hline Borneol & 1165 & 33.5 \\
\hline Terpinene-4-ol & 1177 & 0.9 \\
\hline$\alpha$-terpineol & 1189 & 0.3 \\
\hline Myrtenol & 1194 & 0.2 \\
\hline Verbanol & 1207 & 0.2 \\
\hline chrysanthemyl acetate & 1232 & 0.4 \\
\hline Thymol methyl & 1239 & 0.1 \\
\hline Cis-chrysanthenyl acetate & 1257 & 0.9 \\
\hline Bornyl acetate & 1283 & 12.8 \\
\hline Thymol & 1286 & 1.5 \\
\hline Carvacrol & 1295 & 0.5 \\
\hline Trans- $\beta$-Farnesene & 1448 & 1.7 \\
\hline Germacrene-d & 1474 & 0.2 \\
\hline$\alpha$-farnesene & 1490 & 0.2 \\
\hline Elymol & 1542 & 0.3 \\
\hline Caryophyllene oxide & 1573 & 0.2 \\
\hline Davanone & 1580 & 0.7 \\
\hline$\gamma$-eudesmol & 1625 & 1.2 \\
\hline
\end{tabular}

Abbreviation: RI, Retention Index. 